\title{
Prevalence and Determinants of Neglect and Physical Abuse among Adolescents Living with Human Immunodeficiency Virus (HIV) Infection in Lagos State, Nigeria
}

Suraju Adeyemo1*, Increase I Adeosun ${ }^{2}$, Agatha N David ${ }^{3}$, Gbonjubola 0 Babalola4, Oyewale A Ogunlowo4, Adebayo 0 Jejeloye ${ }^{4}$, Oluwatosin 0 Adeyemo5, Adunola A Pedro ${ }^{4}$ and Olufemi o Oyekunle ${ }^{4}$

${ }^{1}$ Synapse Services, Mangoro, Lagos, Nigeria

${ }^{2}$ Department of Medicine, Benjamin Carson snr. School of medicine, Babcock University, Ilishan-Remo, Nigeria ${ }^{3}$ Nigeria institute of medical research, Yaba, Lagos, Nigeria

${ }^{4}$ Federal neuropsychiatric Hospital, Yaba, Lagos, Nigeria

5Ifako Ijaye General Hospital, Lagos State health service commission, Nigeria

*Corresponding author: Suraju Adeyemo, Synapse Services, number 60 Babapomile Street, Onipetesi Estate, Mangoro, Lagos, Nigeria, Tel: +2348035971942; Email: adeyemosuraju@gmail.com

\section{Abstract}

Background Neglect and physical abuse are common important modifiable psychosocial causes of comorbidity in adolescent living with HIV infection. These adverse childhood experiences can lead to poor adherence to treatment plan and a subsequent development of complications from HIV infection. The purpose of this study was to assess the prevalence of Neglect and Physical abuse in adolescents living with HIV and to determine the variables that are associated with them. Method this was a cross-sectional study carried out among 201 adolescents living with HIV who had a laboratory-confirmed diagnosis of HIV, caregivers' signed consent and were attending an adolescents' out-patient HIV clinic in Lagos state, Nigeria. Data were collected using Socio-demographic Questionnaire, OSLO-3 item social support and Adverse Childhood Experience Scale (ACE). The Statistical Package for Social Sciences (IBM-SPSS) version 24 was used to analyze all collated data. Result Mean age was $13.88( \pm 2.53)$ years, $73.6 \%$ of the participants had a history of Physical abuse, while 29.4\% had a history of Neglect. Mean age in years ( $\mathrm{p}=0.05)$, Fathers Occupation ( $\mathrm{p}=0.09)$, Route of infection $(p=0.045)$ and HIV status of parents $(p=0.021)$ were significantly associated with Neglect. While Mean age at diagnosis $(\mathrm{p}=0.016)$, relationship with mother $(\mathrm{p}=0.012)$, death of parent due to HIV infection ( $\mathrm{p}=0.037)$, and social support $(p=0.003)$ were significantly associated with Physical Abuse. Conclusion Adolescent living with HIV infection 


\section{Psychology \& Psychological Research International Journal}

will need to have regular assessment for the presence of Neglect and physical abuse so as to ensure early intervention in order to prevent the development of any psychological distress that can worsen their illness.

Keywords: Immunodeficiency; Adolescents; Infections; Regression; Neglect

\section{Introduction}

According to the World Health Organization; adolescent age is the period between ages 10 to 19 years, these period is associated with biological changes such as puberty, social and psychological changes associated with awareness of sexuality [1,2]. Adolescents living with Human Immune-deficiency Virus (HIV) infection are faced with difficulties accepting their HIV status and the need for lifelong treatment [1], and have also been reported to be more likely to witness the death of their parent or loved ones on account of HIV/AIDS compared to general population; these makes them easily prone to neglect and/or physical abuse by caregivers who may not be their biological parents $[3,4]$. The presence of chronic illness and infections like HIV have been reported to be associated with higher rate of ACE (neglect, abuse) when compared to general adolescent population [5].

Neglect and physical abuse are common important modifiable psychosocial causes of comorbidity in adolescent HIV/AIDS [6,7]. The rate of abuse in general population was reported to be as high as $25 \%$, but found to be higher among people living with HIV/AIDS $[8,9]$. In previous studies, the prevalence of Neglect among people living with HIV was reported to be between $36.9 \%$ (emotional neglect) and $46.8 \%$ (physical neglect), while the rate of physical abuse was reported to be as high as $51 \%[10,11]$. Factors like male gender, age, level of education, and living with non-biological caregivers, have been shown to be associated with abuse in adolescents $[3,5]$.

It has also been reported in previous studies that the experience of abuse in childhood can lead to poor adherence to treatment plan in individual living with HIV, and that this may eventually results into development of complications from the infection $[6,8,12,13]$. Some literatures reported that child abuse may result into the development of poor coping styles and poor selfassessment, which both then leads to poor adherence $[6,9]$.
In spite of the high prevalence of abuse in people living with HIV, studies on factors associated with Neglect and physical abuse among adolescents with HIV in subSaharan African is scarce, Hence the need for the current study to bridge the gap in knowledge. The objective of this study was to assess the prevalence and correlates of Neglect and physical abuse in adolescents living with HIV in Lagos state, Nigeria. The findings from this study will identify variable that may predispose these group of adolescents to abuse, as well as help indicate the importance for the need to formulate specific child abuse prevention plan in adolescents living with HIV infection.

\section{Methodology}

This was a cross-sectional study carried out among two hundred and one (201) adolescents living with HIV, and attending the outpatient clinic of two western Nigerian health institutions; Lagos state University Teaching Hospital and the Nigerian Institute of Medical Research. Only adolescents; within the ages 10 and 19 years, with laboratory confirmed diagnosis of HIV, who gave an assent, and had caregivers' signed consent to participate in the study, were recruited into the study.

\section{Data collection}

Data was collected with; socio-demographic questionnaire, oslo-3 item social support scale and adverse childhood experience questionnaire.

1. Socio-demographic and illness variable questionnaire detailing (a) child variables like current age, age at diagnosis, gender, level of education, route of infection (b) family variables like HIV status of parent and sibling, who the primary care giver was, family type, loss of parent (s) to HIV

2. Social support was assessed using the "OSLO-3 item social support scale" which has been used by previous Nigerian studies [14].

3. Neglect and Physical abuse were measured with the Adverse Childhood Experience Scale (ACE), which uses a simple scoring method to determine the extent of exposure to childhood trauma. The responses are in "Yes" or "No" format. It has also been used in previous Nigerian study $[15,16]$. 


\section{Psychology \& Psychological Research International Journal}

Ethical approval: Ethical approval was obtained from the research ethics committees of the Lagos State University Teaching Hospital, and the Nigerian Institute of Medical Research. All the participants knew their HIV status prior to their participation in the study, and were all adequately informed about the nature of the study.

Procedure: adolescents at the HIV clinic who met the inclusion criteria were recruited into the study. Between 3 to 4 recruited adolescents seen per clinic day were taken into a separate consulting room where they were allow to fill the socio-demographic, oslo-3 questionnaire and the ACE questionnaire with assistance from their caregiver, and occasional seeking clarifications from the researcher when necessary. All participants were assured of confidentiality.

Statistical Analysis: The Statistical Package for Social Sciences (IBM-SPSS) version 24 was used to analyse all collated data. A frequency table was generated to determine the rate of neglect and physical abuse in the participants. A chi-square test and t- test was used to analyse the association between the independent variables (socio-demographic/ illness related variables) and dependent variable (Neglect, Physical Abuse). A further analysis was done using a regression analysis to identify which of the associated independent variables was predictive of the dependent variable.

\section{Result}

The ages of the participants ranged from 10-19 years, with a mean age of $13.88( \pm 2.53)$ years (Table1). The mean age at diagnosis was $4.43( \pm 4.69)$. About six out of every ten $(61.7 \%)$ participants were male while $38.3 \%$ of the participants were female. The majority $(87.1 \%)$ of the adolescents were born with the HIV infection, $12.9 \%$ contact the infection through blood transfusion or sharing of sharp object (Table 1). Over seven out of ten (73.6\%) participants had a history of physical abuse, while $29.4 \%$ had history of neglect childhood (Table 2).

\begin{tabular}{|c|c|c|}
\hline Variables & Frequency & Percentage (\%) \\
\hline Mean Age $( \pm$ SD) & $13.88 \pm 2.531$ & \\
\hline Mean Age at diagnosis ( \pm SD) & $4.43 \pm 4.689$ & \\
\hline \multicolumn{3}{|l|}{ Gender } \\
\hline Male & 124 & 61.7 \\
\hline Female & 77 & 38.3 \\
\hline \multicolumn{3}{|l|}{ Level of education } \\
\hline Primary & 38 & 18.9 \\
\hline Secondary school & 152 & 75.6 \\
\hline Post-secondary school & 11 & 5.5 \\
\hline \multicolumn{3}{|l|}{ Primary care giver } \\
\hline Biological parent (at least one) & 159 & 79.1 \\
\hline Others & 42 & 20.9 \\
\hline \multicolumn{3}{|l|}{ Family type } \\
\hline Monogamous & 137 & 68.2 \\
\hline Polygamous & 64 & 31.8 \\
\hline \multicolumn{3}{|l|}{ Fathers' occupation } \\
\hline Manager & 35 & 17.4 \\
\hline Professional & 52 & 25.9 \\
\hline Technicians & 28 & 13.9 \\
\hline Clerical worker & 20 & 10 \\
\hline Sales worker & 33 & 16.4 \\
\hline Craft and related worker & 22 & 10.9 \\
\hline Elementary occupation & 6 & 3 \\
\hline Armed forces occupation & 5 & 2.5 \\
\hline \multicolumn{3}{|l|}{ Mothers' occupation } \\
\hline Manager & 13 & 6.5 \\
\hline Professional & 36 & 17.9 \\
\hline Technicians & 6 & 3 \\
\hline
\end{tabular}




\section{Psychology \& Psychological Research International Journal}

\begin{tabular}{|c|c|c|}
\hline Clerical worker & 9 & 4.5 \\
\hline Sales worker & 65 & 32.3 \\
\hline Skilled agricultural/forestry worker & 4 & 2 \\
\hline Craft and related worker & 57 & 28.4 \\
\hline Elementary occupation & 8 & 4 \\
\hline Armed forces occupation & 3 & 1.5 \\
\hline \multicolumn{3}{|l|}{ Relationship with father } \\
\hline Not applicable & 69 & 34.3 \\
\hline Cordial & 123 & 61.2 \\
\hline Not cordial & 9 & 4.5 \\
\hline \multicolumn{3}{|l|}{ Relationship with mother } \\
\hline Not applicable & 56 & 27.9 \\
\hline Cordial & 145 & 72.1 \\
\hline \multicolumn{3}{|l|}{ Death of parent due to HIV } \\
\hline Both parent alive & 111 & 55.2 \\
\hline Father dead & 31 & 15.4 \\
\hline Mother dead & 41 & 20.4 \\
\hline Both parent & 18 & 9 \\
\hline \multicolumn{3}{|l|}{ Route of contact } \\
\hline Born with it & 175 & 87.1 \\
\hline Other route (blood, sharp object) & 26 & 12.9 \\
\hline \multicolumn{3}{|l|}{ HIV of Parent } \\
\hline One parent positive & 92 & 45.8 \\
\hline Both parent positive & 27 & 13.4 \\
\hline Both negative & 82 & 40.8 \\
\hline \multicolumn{3}{|l|}{ HIV status of sibling } \\
\hline Positive & 43 & 21.4 \\
\hline Negative & 158 & 78.6 \\
\hline \multicolumn{3}{|l|}{ Oslo score } \\
\hline Poor social support & 7537.3 & \\
\hline Moderate social support & 86 & 42.8 \\
\hline Strong social support & 40 & 19.9 \\
\hline
\end{tabular}

Table 1: Socio-demographic/illness related variables of adolescents with HIV infection

\begin{tabular}{|c|c|c|}
\hline Variables & Frequency & Percentage (\%) \\
\hline Physical abuse & & 73.6 \\
\hline Yes & 148 & 26.4 \\
\hline No & 53 & \\
\hline Neglect & 59 & 29.4 \\
\hline Yes & 142 & 70.6 \\
\hline No & & \\
\hline
\end{tabular}

Table 2: Prevalence of Neglect and Physical Abuse in adolescents with HIV infection

\section{Chi-square test/ T-test}

Mean age in years $(\mathrm{p}=0.05)$, Fathers Occupation $(\mathrm{p}=0.09)$, Route of infection $(\mathrm{p}=0.045)$ and HIV status of parents $(p=0.021)$ were statistically associated with Neglect. While, Mean age at diagnosis $(\mathrm{p}=0.016)$, relationship with mother $(\mathrm{p}=0.012)$, death of parent due to HIV infection $(\mathrm{p}=0.037)$, and social support $(\mathrm{p}=0.003)$ were the only variable with a statistically significant association with Physical Abuse (Table 3). 


\section{Psychology \& Psychological Research International Journal}

\begin{tabular}{|c|c|c|}
\hline Variables & Neglect(X2) & Physical Abuse(X) \\
\hline Mean age & $1.975^{* 1 \mathrm{t}}$ & $0.843^{\mathrm{t}}$ \\
\hline Mean age at diagnosis & $-1.8 .2^{\mathrm{t}}$ & $-2.430^{* \mathrm{at}}$ \\
\hline Gender & 0.037 & 1.183 \\
\hline Level of education & 1.969 & 0.174 \\
\hline Primary care giver & 0.787 & 3.761 \\
\hline Family type & 0.542 & 0.091 \\
\hline Fathers' occupation & $18.340^{* 2}$ & 5.669 \\
\hline Mothers' occupation & 8.83 & 3.128 \\
\hline Relationship with father & 1.041 & 4.474 \\
\hline Relationship with mother & 0.45 & $8.866^{* \mathrm{~b}}$ \\
\hline Death of parent due to HIV & 1.967 & $8.508^{* \mathrm{c}}$ \\
\hline Route of infection & $8.056^{* 3}$ & 1.354 \\
\hline HIV status of parent & $7.683^{* 4}$ & 0.338 \\
\hline HIV status of sibling & 0.361 & 0.067 \\
\hline Social Support & 1.191 & $11.489^{* \mathrm{~d}}$ \\
\hline
\end{tabular}

*; significant variable, ${ }^{*} 1 ; \mathrm{p}=0.05,{ }^{*} 2 ; \mathrm{p}=0.019,{ }^{*} 3 ; \mathrm{p}=0.045,{ }^{*} 4 ; \mathrm{p}=0.021,{ }^{*} \mathrm{a} ; \mathrm{p}=0.016,{ }^{*} \mathrm{~b} ; \mathrm{p}=0.012,{ }^{*}$; $\mathrm{p}=0.037,{ }^{*}$; $\mathrm{p}=0.003$. $\mathrm{t}$; T-test,

Table 3: Chi square and T-test to analysis of variable associated with Neglect and Physical Abuse in adolescents with HIV infection

\section{Regression Analysis}

Only variable that had significant association in previous analysis (chi-square test, T-test) were entered into the model. The model fitting information shows a significant final model $\left(\mathrm{x}^{2}=24.092, \mathrm{p}=0.001\right)$ with a $16.5 \%$ variance (Nagelkerke $\mathrm{R}^{2}=0.165$ ). Only age at diagnosis and social support showed a significant relationship with physical abuse in the final model. For every unit increase in age at diagnosis, there is a $7.5 \%$ chance of not being physically abuse $(\mathrm{OR}=0.925, \mathrm{p}=0.031)$. Those with poor social support had a $205 \%(\mathrm{OR}=3.055, \mathrm{p}=0.012)$ chance of being physically abused compared to those with strong social support, also, those with moderate social support had a 245\% (OR=3.452, $\mathrm{p}=0.005)$ chance of being physically abuse compared to those with strong social support (Table 4).

\begin{tabular}{|c|c|c|c|c|c|c|c|c|}
\hline \multirow{2}{*}{ physical abuse $^{2}$ (YES) } & \multirow{2}{*}{ B } & \multirow{2}{*}{ Std. Error } & Wald & df & \multirow{2}{*}{ Sig. } & \multirow{2}{*}{ Exp(B) } & \multicolumn{2}{|c|}{ 95\% Confidence Interval for Exp(B) } \\
\hline Age at diagnoses & -0.078 & 0.036 & 4.652 & 1 & $\mathbf{0 . 0 3 1}$ & $\mathbf{0 . 9 2 5}$ & 0.862 & 0.993 \\
\hline Relationship with Mother & & & & & & & & \\
\hline Not applicable & -0.568 & 0.461 & 1.513 & 1 & 0.219 & 0.567 & 0.229 & 1.401 \\
\hline cordial & $0^{\mathrm{b}}$ &. &. & 0 &. &. & &. \\
\hline Experienced death of parent & & & & & & & & \\
\hline Both parent alive & 0.836 & 0.662 & 1.594 & 1 & 0.207 & 2.308 & 0.630 & 8.456 \\
\hline Father dead & 0.762 & 0.746 & 1.042 & 1 & 0.307 & 2.142 & 0.496 & 9.247 \\
\hline Mother dead & 0.502 & 0.627 & 0.641 & 1 & 0.423 & 1.651 & 0.484 & 5.640 \\
\hline Both parent Dead & $0^{\mathrm{b}}$ &. &. & 0 &. &. &. &. \\
\hline Social support & & & & & & & & 7.312 \\
\hline Poor & 1.117 & 0.445 & 6.288 & 1 & $\mathbf{0 . 0 1 2}$ & $\mathbf{3 . 0 5 5}$ & 1.276 & 8.163 \\
\hline moderate & 1.239 & 0.439 & 7.963 & 1 & $\mathbf{0 . 0 0 5}$ & $\mathbf{3 . 4 5 2}$ & 1.460 &. \\
\hline strong & $0^{\mathrm{b}}$ &. &. & 0 &. &. & &. \\
\hline
\end{tabular}

a The reference category is: NO

b this parameter is set to Zero because of redundancy

Table 4: Multinomial Regression analysis of variable associated with Physical Abuse. 


\section{Psychology \& Psychological Research International Journal}

Age in years, fathers' occupation, HIV status of sibling, HIV status of parent and route of contact were entered into a multivariate regression model for Neglect. The model fits appropriately $\left(\mathrm{x}^{2}=34.032, \mathrm{p}=0.001\right)$ with a variance of $22.2 \%$ (Nagelkerke $\mathrm{R}^{2}=0.222$ ). Only age in years and route of infection had a significant association with Neglect in the final model. For every unit increase in age, there was a $24.5 \%$ of participant being neglected $(\mathrm{OR}=1.245, \mathrm{p}=0.003)$. Also participants who were born with HIV infection had 4.258 odd of being neglected compared to those who contacted HIV through blood transfusion or sharing of sharp object (Table 5).

\begin{tabular}{|c|c|c|c|c|c|c|c|c|}
\hline \multirow[t]{2}{*}{ Neglecta $^{\text {(YES) }}$} & \multirow[t]{2}{*}{ B } & \multirow[t]{2}{*}{ Std. Error } & \multirow[t]{2}{*}{ Wald } & \multirow[t]{2}{*}{ df } & \multirow[t]{2}{*}{ Sig. } & \multirow[t]{2}{*}{$\operatorname{Exp}(B)$} & \multicolumn{2}{|c|}{$\begin{array}{c}\text { 95\% Confidence Interval for } \\
\text { Exp(B) }\end{array}$} \\
\hline & & & & & & & Lower Bound & Upper Bound \\
\hline Age in years & 0.219 & 0.074 & 8.734 & 1 & 0.003 & 1.245 & 1.076 & 1.439 \\
\hline \multicolumn{9}{|l|}{ HIV status of sibling } \\
\hline Positive & 0.465 & 0.648 & 0.516 & 1 & 0.473 & 1.593 & 0.447 & 5.668 \\
\hline Negative & $0^{\mathrm{b}}$ & . & . & 0 & . & . & . & . \\
\hline \multicolumn{9}{|l|}{ FATHERS Occupation } \\
\hline Manager & -0.926 & 1.044 & 0.786 & 1 & 0.375 & 0.396 & 0.051 & 3.068 \\
\hline Professional & -1.97 & 1.032 & 3.646 & 1 & 0.056 & 0.139 & 0.018 & 1.053 \\
\hline Technicians & -1.313 & 1.073 & 1.498 & 1 & 0.221 & 0.269 & 0.033 & 2.202 \\
\hline Clerical workers & 0.386 & 1.094 & 0.125 & 1 & 0.724 & 1.471 & 0.172 & 12.566 \\
\hline Sales workers & -1.182 & 1.066 & 1.228 & 1 & 0.268 & 0.307 & 0.038 & 2.481 \\
\hline Craft and related workers & -1.29 & 1.086 & 1.412 & 1 & 0.235 & 0.275 & 0.033 & 2.311 \\
\hline Elementary occupations & -0.746 & 1.328 & 0.315 & 1 & 0.574 & 0.474 & 0.035 & 6.404 \\
\hline Armed forces Occupation & $0^{\mathrm{b}}$ &. & . & 0 & . &. &. & . \\
\hline \multicolumn{9}{|l|}{ HIV status of Parents } \\
\hline One Parent positive & -0.316 & 0.41 & 0.591 & 1 & 0.442 & 0.729 & 0.326 & 1.63 \\
\hline Both Parents positive & 0.548 & 0.811 & 0.457 & 1 & 0.499 & 1.73 & 0.353 & 8.475 \\
\hline Both Parents negative & $0^{\mathrm{b}}$ &. &. & 0 & . & . &. & . \\
\hline \multicolumn{9}{|l|}{ ROUTE of infection } \\
\hline Birth & 1.449 & 0.656 & 4.875 & 1 & 0.027 & 4.258 & 1.177 & 15.408 \\
\hline $\begin{array}{c}\text { Blood transfusion/ sharp } \\
\text { object }\end{array}$ & $0^{\mathrm{b}}$ & . & . & 0 & . & . & . & . \\
\hline
\end{tabular}

a The reference category is: NO; $\mathbf{b}$ this parameter is set to Zero because of redundancy

Table 5: Multinomial Regression analysis of variable associated with Neglect.

\section{Discussion}

The findings from a Nigerian National Survey carried out in 2015 to determine the prevalence of child abuse among children below the age of 18 years, shows that about six in ten $(60 \%)$ children had a history of child abuse while, about one in two (50\%) had history of physical abuse [17]. In the current study, a higher prevalence of physical abuse $(73.6 \%)$ was found among adolescent with HIV infection; this may be an indication that adolescents living with HIV infection are more prone to physical abuse compared to adolescents in general population. It can also be explained by the fact that the presence of chronic illness like HIV infection increases the prevalence of physical abuse ${ }^{5}$. Inversely, the prevalence of neglect (29.4\%) in the current study was lower than that reported among adolescent in general population and also among people living with HIV who were also illicit drug users $[10,18]$.

This study shows that the older the age at diagnosis of participants, the lower the likelihood of being physically abused. Although age has been reported in previous studies to be associated with physical abuse, the direction of relationship was not specified in them [3,5]. Also, because participants with poor and moderate social support in the current study were more likely to be physically abused compared to those with good social 


\section{Psychology \& Psychological Research International Journal}

support, it is not surprising that relationship with mother and death of parent due to HIV/AIDS; which are two factors that may affect the strength of participants social support, were also significantly associated with physical abuse among participants. Although compared to social support, relationship with mother and death of parents were not predictive of physical abuse. It is important for clinicians to formulate a plan on how to encourage a strong social support for adolescent attending their HIV out-patient clinic.

Age of participants and route of infection was shown in the current study to be associated with Neglect. The older the age of participants, the more likelihood such an individual will be neglected by caregivers. Also participants who were born with HIV-infection had a tendency of being more neglected than those who were infected through blood transfusion or sharp object. This findings help emphasis similar report from previous studies $[3,5,13]$. Similarly, participants' fathers' occupation was found in the current study to be associated with Neglect. Although there was scarcity of study in this environment that assessed the association between fathers' occupation and Neglect among adolescents living with HIV infection, the findings in the current study has open up an opportunity for further studies.

\section{Conclusion}

This study reported a high prevalence of Neglect and physical abuse among adolescent living with HIV, it also shows that neglect can be modified by the presence of variable like age and being born with HIV infection. While, age at diagnosis and absent of good social support can predispose to physical abuse. The implication of these is that adolescent living with HIV needs to have regular assessment for the presence of Neglect and physical abuse especially those with predisposing factors; this will help in early detection of abuse, intervention and prevention of further worsen their illness [19].

\section{Conflict of Interest}

The authors declare no potential conflicts of interest with respect to the research, authorship, and/or publication of this article.

\section{Acknowledgement}

This work was made possible by the help of all the members' of the paediatric and hematology department of Lagos State University Teaching Hospital (LASUTH), and of the adolescent clinic of Nigerian Institute of Medical Research Yaba (NIMR), Lagos. I want to sincerely appreciate you all for providing an enabling environment for this study.

My gratitude also go to all the participants in this study for their patient and understanding, and to $\mathrm{Mr} \mathrm{Oba}$ of the NIMR for his support and guidance.

Thank you all for making this a reality.

\section{References}

1. Naswa S, Marfatia YS (2010) Adolescent HIV/AIDS: Issues and challenges. Indian J Sex Transm Dis. 31(1): 1-10.

2. Graber JA (1996) Adolescence: Social Patterns, Achievements and Problems, 46-52.

3. Gillian M, Donald C, Rachel V, Samuel A, David A, et al. (2013) Child abuse and neglect among orphaned children and youth living in extended families in sub-Saharan Africa: What have we learned from qualitative inquiry? Vulnerable Child Youth Stud 8(4): 338-352.

4. Naicker SN, Norris SA, Mabaso M, Richter LM (2017) An analysis of retrospective and repeat prospective reports of adverse childhood experiences from the South African Birth to Twenty Plus cohort. PLoS One 12(7): 1-19.

5. Stanley DR, Weili LU, Klim TM, Mary KJ, Cournos F (2007) Correlates of Adverse Childhood Events Among Adults With Schizophrenia Spectrum Disorders. Physiatr Serv 58(2): 245-253.

6. Brian Wells Pence (2009) The impact of mental health and traumatic life experiences on antiretroviral treatment outcomes for people living with HIV / AIDS. J Antimicrob Chemother 63(4): 636-640.

7. Leserman J, Pence BW, Whetten K, Mugavero MJ, Thielman NM (2007) Relation of lifetime trauma and depressive symptoms to mortality in HIV. Am J Psychiatry 164(11): 1707-1713.

8. Brief DJ, Bollinger AR, Vielhauer MJ, BergerGreenstein JA, Morgan EE, et al. (2004) Understanding the interface of HIV, trauma, posttraumatic stress disorder, and substance use and its 


\section{Psychology \& Psychological Research International Journal}

implications for health outcomes. AIDS Care 16(S1): 97-120.

9. Dlamini PS, Kohi TW, Uys LR, Phetlhu RD, Chirwa ML, et al. (2007) Verbal and Physical Abuse and Neglect as Manifestations of HIV/AIDS Stigma in Five African Countries. Public Health Nursing 24(5): 389-399.

10. Georgia W, Steven JC, Milloy MJ, Jiezhi Q, Thomas K, et al. (2011) High prevalence of childhood emotional, physical and sexual trauma among a Canadian cohort of HIV-seropositive illicit drug users. AIDS CARE 23(6): 714-721.

11. Gretchen AC, Katherine A, Kathryn M, Jonathan ME (2009) Child Abuse in Young, HIV-Positive Women: Linkages to Risk. Qual Health Res 19(12): 17551768.

12. Mugavero M, Ostermann J, Whetten K, Leserman J, Swartz M, et al. (2006) Barriers to antiretroviral adherence: the importance of depression, abuse, and other traumatic events. AIDS Patient Care STDS 20(6): 418-428.

13. Valerie JE, Robert FA, David GU, Shante RD, Felitti VJ (2007) Adverse Childhood Experiences and Smoking Persistence in Adults with SmokingRelated Symptoms and Illness. Perm J 11(2): 5-13.
14. Abiola T, Lawal I, Habib ZG (2015) Psychological distress due to academic stress among clinical students in a Nigerian tertiary institution: Comparison between medical and physiotherapy students. Niger J Basic Clin Sci 12(2): 81-85.

15. Oladeji BD, Makanjuola VA, Gureje $O$ (2010) Familyrelated adverse childhood experiences as risk factors for psychiatric disorders in Nigeria. $\mathrm{Br} \mathrm{J}$ Psychiatry 196(3): 186-191.

16. Olalekan TK (2015) A Validation of the Adverse Childhood Experiences Scale in Nigeria. Research on Humanities and Social Sciences 5(11): 18-23.

17. UNICEF Nigeria (2015) Nigeria Violence Against Children Survey.

18. Mahram M, Hosseinkhani Z, Nedjat S, Aflatouni A (2013) Epidemiologic Evaluation of Child Abuse and Neglect in School-Aged Children of Qazvin Province, Iran. Iran J Pediatr 23(2): 159-164.

19. Brian WP, Michael JM, Tandrea JC, Jane L, Nathan MT, et al. (2012) Childhood trauma and health outcomes in HIV-infected patients: An exploration of causal pathways Brian. J Acquir Immune Defic Syndr 59(4): 409-416.

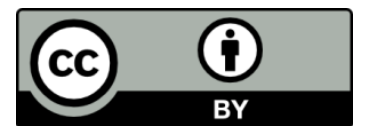

